\title{
METALINGUAGEM SEMIÓTICA: EMPRÉSTIMOS E REDEFINIÇÕES
}

\section{THE SEMIOTIC METALANGUAGE: BORROWINGS AND REDEFININGS}

\author{
Jean Cristtus Portela \\ UNESP - Faculdade de Arquitetura, Artes e Comunicação \\ UNESP - Faculdade de Ciências e Letras de Araraquara
}

\begin{abstract}
RESUMO: Este trabalho discute o problema da terminologia e da conceitualização na construção da metalinguagem semiótica. $\mathrm{O}$ ponto de partida para essa discussão é o ideário científico de pensadores como C. S. Peirce, R. Bastide e É. Benveniste, que entendem que a criação de uma nova ciência tem como exigência a elaboração de uma nova e precisa terminologia. Essa posição é relativizada e ampliada pela visão de A. J. Greimas, que defende a centralidade da conceitualização, em detrimento da formalização e da produção terminológica. Por fim, propõem-se e analisam-se dois tipos de elaboração metalinguística baseados no diálogo com teorias e disciplinas precedentes: o empréstimo e a redefinição.
\end{abstract}

PALAVRAS-CHAVE: Metalinguagem; Semiótica; Terminologia; Conceito; Termo; Algirdas Julien Greimas.

\begin{abstract}
This paper deals with the issue of terminology and conceptualization in the construction of the semiotic metalanguage. The starting point of this discussion is the scientific thought of C. S. Pierce, R. Bastide and É. Benveniste, who understand that the creation of a new science requires a new and precise terminology. This position is relativized and magnified by the point of view of A. J. Greimas, who defends the centrality of the conceptualization rather than the formalization and the terminological production. Thus, this study proposes and analyses two types of metalinguistic elaboration based on the dialogue with previous theories and disciplines: the borrowing and the redefining.
\end{abstract}

KEYWORDS: Metalanguage; Semiotics; Terminology; Concept; Term; Algirdas Julien Greimas.

\section{Introdução}

A qualidade da bebida que bebemos depende muito mais do café do que da cafeteira. A formalização (e, em geral, os métodos lógico-matemáticos introduzidos artificialmente) é a cafeteira.

A.J. Greimas (1980, p. 54) ${ }^{1}$

\footnotetext{
${ }^{1}$ Todas as traduções das obras em língua estrangeira são nossas.
} 
[O léxico científico] tomado na comunicação, comporta-se como qualquer outro léxico: difusão, empréstimos, analogias intervêm e são acompanhadas de mudanças de sentido, a sinonímia e a polissemia persistem, ligadas à atividade científica ela mesma; em todos os casos observa-se um trabalho constante de reformulação.

A Semiótica discursiva é uma teoria do discurso frequentemente considerada difícil pela especificidade de sua metalinguagem. Não raramente, o pesquisador e o estudante neófitos queixam-se do "semiotiquês", esse dialeto de léxico supostamente bem (inter)definido, verdadeiro labirinto hipertextual (FIORIN, 2008, p. 9), que é familiar aos leitores dos dois tomos do Dicionário de A. J. Greimas e J. Courtés e do enciclopédico Tensão e Significação, de J. Fontanille e C. Zilberberg.

Dentro e fora das ciências humanas, não foram poucos os estudiosos que defenderam a ideia de que, na produção da ciência, novas concepções teóricas devem ser acompanhadas de uma igualmente nova terminologia. Entre os principais defensores dessa ideia, particularmente no âmbito das ciências humanas, nos séculos XIX e XX, estão C. S. Peirce, R. Bastide e É. Benveniste.

Uma leitura cuidadosa da metalinguagem arrolada e definida nos dois tomos do Dicionário nos mostra, como costuma acontecer na produção de textos e discursos, que a criação terminológica e a criação conceitual não se produzem por "geração espontânea", a partir de "um grau zero do pensamento", e mantêm um intercâmbio mais ou menos explícito, por meio de empréstimos e de redefinições, com a tradição científica em que está imersa e da qual, por vezes, se esforça em se separar.

A seguir, apresentaremos (1) algumas ideias a respeito da produção terminológica e conceitual no campo científico, de modo a preparar o terreno para (2) colocar em questão o papel da metalinguagem na economia da teoria semiótica, especialmente na sua forma de produção e circulação por meio de dicionários, e, finalmente, (3) abordaremos os empréstimos e redefinições que foram operados em torno do conceito de "ponto de vista" e de seus correlatos "perspectiva" e "focalização" 2 , e que marcaram, em sentido amplo, a construção da identidade e da alteridade da Semiótica em face às teorias da língua, da literatura e do discurso.

\section{Termo ou conceito?}

Distinguiremos "termo" de "conceito" por meio de uma definição corrente nos estudos de Terminologia:

[...] o termo [...] é uma designação por meio de uma unidade linguística de um conceito definido em uma língua de especialidade. O termo é, portanto,

\footnotetext{
${ }^{2}$ As entradas "ponto de vista", "perspectiva" e "focalização" foram tomadas do primeiro tomo do Dicionário nessa sequência a fim de conservar uma ordem de análise que fosse do conceito englobante (ponto de vista) ou simplesmente distinto (perspectiva) ao conceito englobado (focalização). O texto integral das entradas, digitalizado a partir de Greimas e Courtés (2008), pode ser consultado, respectivamente, nos Anexos A, B e C. Limitamo-nos à análise tão somente das entradas do primeiro tomo do Dicionário, que nos pareceram suficientemente esclarecedoras sobre as operações de empréstimo e redefinição que procuramos descrever. No segundo tomo do Dicionário, Greimas e Courtés (1986) farão constar novamente as três entradas com complementos e propostas de Jacques Fontanille e críticas de Françoise Bastide.
}

Disponível em: http://seer.fclar.unesp.br/casa 
uma unidade lexical com um conteúdo específico dentro de um domínio específico (BARROS, 2004, p. 38-9).

Dessa definição depreende-se que o "termo" é a denominação do "conceito", e este, por sua vez, é pertinente como "conteúdo específico" em uma dada especialidade, em nosso caso, a Semiótica:

[A língua de especialidade é um] sistema de comunicação oral ou escrita usado por uma comunidade de especialistas de uma área particular do conhecimento (PAVEL; NOLET apud BARROS, 2004, p. 39).

Para o semioticista, talvez não seja fácil pensar sua prática analítica como atravessada, e até mesmo viabilizada, por uma língua de especialidade. Segundo essa concepção, o semioticista deveria renunciar a qualquer narcisismo para se enquadrar na vala comum daqueles que, defendendo aquilo que pode ser um projeto de vida, exercem uma atividade profissional, nos seguintes termos explicitados por Maria da Graça Krieger (2006), que nos oferece uma hipótese sobre a abundância e a relevância do léxico especializado na atualidade:

Na realidade, o século XX é o cenário maior de grande desenvolvimento e consolidação da terminologia, quer como instrumental linguístico a serviço da comunicação profissional, quer como campo de conhecimento. O crescimento desse componente linguístico, denominado de léxico especializado, está diretamente relacionado à exponencial ampliação do conhecimento científico e da produção tecnológica, uma das mais marcantes características do final do milênio. Em consequência, novos termos surgem e se multiplicam para "batizar" as inovações que surgem cotidianamente (KRIEGER, 2006).

Ar do tempo? O fato é que, no campo das teorias do discurso, o século XX foi marcado pela exigência de cientificidade, exigência que Greimas assumiu enquanto projeto de vocação científica e que nos legou o conforto e o desconforto de que goza o semioticista entre os demais interessados pela linguagem. Sentimo-nos confortáveis porque nós "nos entendemos", partilhamos mais ou menos os mesmos termos que, se tudo corre bem, recobrem os mesmos conceitos. Mas, ainda assim, algo não vai bem, algo nos causa desconforto: nossos "vizinhos" pouco ou nada nos compreendem, nossos termos não são tão precisos e articulados ao conjunto da teoria como imaginamos, muitos de nossos conceitos caem em desuso ou em completo descrédito no limiar de cada década.

E, entretanto, podemos, ainda, nos dizer (e nos reconfortar): o projeto era e é novo, arrojado, indômito até, e exige uma intensa atividade de conceitualização que nos remete forçosamente à diversidade e à novidade terminológicas.

\section{0 partido tomado da cientificidade e da criação terminológica}

Em "A ética da terminologia" (1903), de Charles Sanders Peirce, podemos encontrar, de forma condensada e elaborada ao mesmo tempo, o ideário científico herdado das ciências naturais que grassava no pragmatismo americano da época. As seguintes passagens do ensaio ilustram o partido peirciano sobre a terminologia: 
A trama de todo pensamento e de toda pesquisa são símbolos, e a vida do pensamento e da ciência é a vida inerente aos símbolos.

[...]

É desejável que qualquer ramo da ciência tenha um vocabulário que forneça uma família de palavras cognatas para cada conceito científico, e que cada palavra tenha um único e exato significado, a menos que seus diferentes significados se refiram a objetos de diferentes categorias que nunca poderão ser confundidas umas com as outras.

$[\ldots]$

A ciência está continuamente ganhando novos conceitos, e todo novo conceito científico deveria receber uma nova palavra ou, melhor, uma nova família de palavras cognatas.

[...]

A primeira regra de bom gosto ao escrever é usar palavras cujos significados não serão mal interpretados; e se o leitor não conhece os significados das palavras, é infinitamente melhor que ele saiba que não os conhece.

[...]

Todo aquele que deliberadamente usar uma palavra ou outro símbolo em qualquer outro sentido que não o que lhe foi conferido por seu único e legítimo criador comete uma vergonhosa ofensa contra o inventor do símbolo e contra a ciência, e torna-se dever dos demais encarar tal ato com desprezo e indignação (PEIRCE, 1995, p. 39-42).

Percebemos nesses excertos a posição exigente de Peirce em relação à produção de conhecimento, segundo regras estritas de um método lógico-formal que não admite o contraditório e estigmatiza a imprecisão, a mistura ${ }^{3}$, em suma. Embora partidário de concepções inovadoras sobre a semiose, a ação dos signos, que para ele se desenvolveria de modo ilimitado e contínuo, Peirce revela nesse ensaio uma visão conservadora sobre a semiose no campo da atividade científica, que deveria ser controlada, mediada, por uma terminologia rigorosa.

Anos depois, no final dos anos 1950, não é diferente a posição que revela Roger Bastide, em sua "Introdução ao uso do termo estrutura" (1959), sobre a importância da precisão terminológica e do obstáculo que é sua ausência ao projeto das ciências humanas:

Nenhuma ciência conseguiu realizar progressos substanciais sem dispor de um vocabulário técnico perfeito. [...] Entretanto, as ciências humanas e, em especial, as ciências sociais, ainda não apresentaram esse vocabulário técnico perfeito, indispensável aos seus futuros progressos. Com efeito, apresentaram elas diversos vocabulários técnicos, mas cada qual feito por um autor, fato este que vem impossibilitar o trabalho comum (BASTIDE, 1971, p. 1).

Vocabulário "perfeito", "futuros progressos"... Essas considerações evocam nossas expectativas mais guardadas e hoje praticamente inconfessáveis: resquícios do tempo em que se referia a uma ciência formal como a Linguística como sendo uma "ciência-piloto"?

\footnotetext{
${ }^{3}$ Utilizamos neste trabalho os termos mistura e triagem na acepção que lhes é corrente na Semiótica tensiva, em especial nas definições reunidas no capítulo "Valor" de Tensão e significação (FONTANILLE; ZILBERBERG, 2001, p. 39-59).
} 
Em uma perspectiva muito próxima das posições de Peirce e Bastide, É. Benveniste, em "Gênese do termo "científico"” (1969), explicita de um modo muito particular a relação entre "termo" e "conceito" e afirma um programa forte de dominação, ou melhor, "imposição" de nossos pontos de vista científicos:

A constituição de uma terminologia própria marca, em toda ciência, o advento ou o desenvolvimento de uma conceitualização nova, assinalando, assim, um momento decisivo de sua história. Poder-se-ia mesmo dizer que a história particular de uma ciência se resume na de seus termos específicos. Uma ciência só começa a existir ou consegue se impor na medida em que faz existir e em que impõe seus conceitos, através de sua denominação. Ela não tem outro meio de estabelecer sua legitimidade senão por especificar seu objeto denominando-o, podendo este constituir uma ordem de fenômenos, um domínio novo ou um modo novo de relação entre certos dados. O aparelhamento mental consiste, em primeiro lugar, de um inventário de termos que arrolam, configuram ou analisam a realidade. Denominar, isto é, criar um conceito, é, ao mesmo tempo, a primeira e última operação de uma ciência (BENVENISTE, 1989, p. 250).

A julgar por esse excerto, para Benveniste, a questão da metalinguagem e de seu bom uso na produção da ciência parece se dar explicitamente mais no campo de uma sociologia do conhecimento ou história das ideias, na medida em que ele evoca valores como pertencimento, prevalência e legitimidade, do que propriamente no interior de um dado projeto epistemológico.

\section{A metalinguagem não é um clube de discurso}

Em "Notes sur le métalangage", Greimas (1980) vai explicitar o desconforto com a metalinguagem que mencionamos anteriormente por meio de afirmações como "as pessoas de bem nos pedem que falemos de maneira simples, como todo mundo" ou, ainda, "do ponto de vista sociolinguístico, a situação da Semiótica é desconfortável" (GREIMAS, 1980, p. 48).

O problema da metalinguagem é enfrentado em toda a sua dimensão, especialmente em relação às "reações adversas" que o "semiotiquês" causa:

Por que tantos protestos [sobre a metalinguagem]? É o problema da diferenciação cultural de uma comunidade linguística em socioletos (clubes de discurso) e conotações sociais que desenvolve sua existência e suas manifestações: 1) $\mathrm{O}$ emprego da metalinguagem pode ser/parecer "terrorista"; 2) A reação pode ser: a imitação, a rejeição, o contra-ataque ou a acusação (justificada ou não) de fazer uso de jargão (GREIMAS, 1980, p. 48).

Reconhecida a dimensão social do uso da metalinguagem em Semiótica, o bom lituano vai orientar a discussão sobre a metalinguagem na direção que ele imagina ser apropriada, o que, como era de se esperar, não se limita a uma reflexão de ordem socioletal sobre a metalinguagem, mas recentra a questão no âmbito do projeto científico da própria Semiótica: 
É preciso reconhecer: a metalinguagem não é uma linguagem no sentido estrito do termo, isto é, "um meio de comunicação" que permite que os membros de um "clube" se compreendam. Ela tem uma finalidade própria, a descrição ou a construção de um objeto científico: a determinação das partes em relação ao todo (e inversamente), seu funcionamento, os percursos que permitem produzir, a partir de regras gerais, objetos particulares, etc. Em suma, a construção de uma teoria (GREIMAS, 1980, p. 52).

A metalinguagem não é um dialeto, não é a senha para o bom convívio científico, mas, antes, a manifestação lexical de uma fina rede conceitual que se organiza por meio de dependências, de modo a explicitar e a descrever a complexidade das semióticasobjeto.

Quando se considera a metalinguagem segundo essa perspectiva, a sua produção torna-se um processo vagaroso e complexo, que avança a partir da análise e da confrontação (a descrição semântica) e da tentativa de estabilização da rede conceitual:

Existe uma fase prévia na elaboração de uma teoria formal, é uma fase de conceitualização. Ela compreende dois níveis, duas problemáticas distintas: a) a descrição semântica propriamente dita; b) a construção conceitual (GREIMAS, 1980, p. 52).

Às etapas de descrição semântica e construção conceitual, Greimas acrescentará a etapa final de formalização, esta última sendo mais superficial e menos necessária do que as outras, a julgar pela epígrafe que deflagrou o presente trabalho: "A qualidade da bebida que bebemos depende muito mais do café do que da cafeteira. A formalização (e, em geral, os métodos lógico-matemáticos introduzidos artificialmente) é a cafeteira" (GREIMAS, 1980, p. 54).

\section{O Dicionário de Semiótica: lugar de construção da teoria e da metalinguagem}

A demanda explícita por uma metalinguagem bem formulada, cuja conceitualização abre caminho para a escolha terminológica e para a formalização, passou a ser, a partir do final dos anos 1970, com a publicação do Dicionário e dos primeiros manuais de Semiótica (COURTÉS, 1976; GROUPE D'ENTREVERNES, 1979; HÉNAULT, 1979), um elemento programático e identitário importante entre os praticantes da Semiótica de origem greimasiana.

A publicação, em 1979, do Dicionário de Semiótica, de Greimas e Courtés (2008), parece tributária desse esforço, por um lado, de difusão das práticas analíticas da Semiótica e, por outro, de um programa de "gestão da teoria", de demarcação de terreno e contenção ou guarda de seus nascentes e moventes termos de primeira época. Basta lembrar que um termo como "figurativo", que acabou por se impor a partir dos anos 1970, conheceu sucessivas elaborações terminológicas, como, por exemplo, "cosmológico", "exteroceptivo" (entrada "exteroceptividade"), "semiológico" e "prático", todas registradas no Dicionário, que é a um só tempo enciclopédico e hesitante ou polêmico em relação à triagem metalinguística.

Pode-se dizer que o Dicionário mais lançou do que fez propriamente conhecer as bases da Semiótica. A opção por essa solução lexicográfica, que pode ser considerada original e tipicamente greimasiana, vem ao encontro de exemplos tão basilares quanto clássicos na Semiótica europeia. Como Saussure, que definiu, em notas diversas e no Curso (SAUSSURE, 2002, p. 262; SAUSSURE, 2005, p. 32-35), o escopo e o caráter da Semiologia 
antes mesmo que ela viesse a se desenvolver, ou, ainda, Hjelmslev, que fez constar ao final de seus Prolegômenos uma lista de 108 definições de termos essenciais à sua teoria da linguagem (HJELMSLEV, 2003, p. 137-141), Greimas e Courtés pareciam estar de acordo a respeito do valor programático das definições.

Em seu prólogo ao Dicionário, Greimas e Courtés (2008, p. 11), ao esboçarem o quadro epistemológico da época, em que a Linguística "[...] com sua tradição mais do que secular havia [...] enveredado pelo caminho de um rigor lógico-matemático" e as correntes semióticas "de inspiração metafísica ou ideológica" conheciam um "esgotamento [...] previsível", apontam a necessidade de um "esforço não de unificação, mas, antes, de homogeneização, para instaurar, ainda que com certo partidarismo, um lugar de aproximação, de comparação e avaliação".

É a esse "partidarismo", a esse movimento de triagem conceitual e terminológica, que Paolo Fabbri (1992) alude em "Introduction à un dictionnaire sans moyens termes" (1986), que serve de prefácio à tradução italiana do Dicionário. Para o semioticista italiano, o Dicionário sustenta com maestria o seu delicado equilíbrio nos princípios de pertinência e adequação, mantendo sua coerência pelo uso do princípio de pertinência por adequação horizontal (termos monossêmicos em relação de coerência e coesão) e por adequação vertical (com a linguagem objeto descrita). Grosso modo, três seriam os pontos, para Fabbri, que ficam patentes na leitura do Dicionário, segundo a avaliação que ele fazia sem "complacência", indicando "lacunas imperdoáveis" como a do verbete "paixão" (FABBRI, 1992, p. 16): (1) o Dicionário faz homologações teóricas provisórias, (2) omite-se sobre temas importantes e (3) pensa ignorar as modas, mas não está à prova delas.

A leitura de Fabbri sobre o Dicionário explicita, em linhas gerais, problemas recorrentes que a "solução lexicográfica" mencionada anteriormente trouxe para a produção da teoria semiótica e para a sua circulação nas esferas acadêmicas. Essa situação chega ao seu ápice quando é publicado, em 1986, o segundo tomo do Dicionário, em que Greimas e Courtés figuram apenas como organizadores e autores de poucos verbetes e em que os verbetes são redigidos em seu conjunto por vinte colaboradores. Além disso, cada verbete do segundo tomo do Dicionário é identificado, de início, com os códigos N, C, D ou P (N = nova entrada; $\mathrm{C}=$ complementos; $\mathrm{D}=$ debate $\mathrm{P}=$ proposta) e, ao final, é assinado pelas iniciais de seu redator.

Poucos semioticistas souberam como H. Parret - que não participou da elaboração do segundo tomo - apontar os riscos que essa babel autoral e metalinguística que é o Dicionário de 1986 poderia acarretar para o desenvolvimento da Semiótica. Em "Les avenirs de la Sémiotique" (1986), texto reunido em um número da Actes Sémiotiques Bulletin intitulado "Autour d'un dictionnaire", Parret (1986, p. 9) afirma sair em defesa do "protossemioticista" ao levantar uma série de pontos problemáticos em relação ao texto do segundo tomo do Dicionário. Esses pontos ilustram de maneira bastante clara os problemas ligados a uma conceitualização inacabada e à ausência de uma efetiva e coerente formalização. Eis alguns dos pontos - além dos erros de tipografia e dos equívocos ou omissões de referências bibliográficas - que nos parecem mais contundentes: 1) A profusão dos estilos; 2) A domesticação do charme (tentativas de sedução por meio de modismos); 3 ) A pseudossemiotização de noções filosóficas; 4) As armadilhas da formalização; 5) A arbitrariedade das entradas e o recalque das problemáticas; 6) O perspectivismo (o partido tomado na escolha) dos conteúdos; e 7) A relação paradoxal do segundo tomo (o filho) com o primeiro (o pai).

Por mais penetrantes que sejam cada uma dessas críticas, seu interesse reside menos no que elas têm de justificado e pertinente e mais na constatação geral de que a 
empreitada do segundo tomo do Dicionário equivale a um momento crítico da Semiótica e de sua metalinguagem. De certo modo, esse momento crítico da Semiótica antecipou em termos de efeitos na comunidade de semioticistas, o cenário pós-greimasiano em que a Semiótica se desenvolveria dez ou vinte anos depois, no qual os conceitos e termos se multiplicam exponencialmente e caem em desuso com a mesma velocidade.

\section{Empréstimos e redefinições}

Definido pelo Houaiss Eletrônico como "ato de emprestar" e "aquilo que se empresta" - ao passo que "emprestar" seria "pôr à disposição; ceder temporariamente" -, o lexema "empréstimo" evoca neste trabalho o sentido que adquiriu na Linguística histórica e na Sociolinguística. Nessa acepção, que não se distancia da acepção do Houaiss, um empréstimo pode ser definido como a operação em que "um falar A usa e acaba por integrar uma unidade ou um traço linguístico que existia precedentemente num falar B e que A não possuía" (DUBOIS, 2011, p. 209). Essa operação pode se dar por integração parcial ou total. O empréstimo, no português brasileiro, por exemplo, do lexema "site" do inglês é um caso de integração parcial: tomou-se a forma da língua de origem sem integração fonológica e ortográfica. No caso do empréstimo de "apagón" ou "blackout", respectivamente do espanhol platino e do inglês, a integração foi completa, como se pode perceber nos lexemas "apagão" e "blecaute", que apresentam integrações fonológicas, morfológicas e ortográficas.

Os empréstimos de que tratamos nesta seção não ocorrem no nível de pertinência linguístico das unidades de caráter fonológico, mórfico ou sintático, mas nos níveis de pertinência lexical e discursivo, manifestando-se pela introdução, na língua de especialidade da Semiótica, de termos herdados de outros domínios teóricos, por meio de citações e alusões, em um verdadeiro processo de intertextualidade. É esse o caso do termo "ponto de vista" e de seus correlatos "perspectiva" e "focalização" no Dicionário de Semiótica, termos esses cuja suposta paternidade é atribuída à Teoria Literária, mais especialmente a Gérard Genette. Foi a partir das ideias de C. Brooks \& R. P. Warren, e W. Booth, N. Friedman, J. Pouillon e T. Todorov, dentre outros, que Genette, em seu célebre Discours du Récit (1972), reconfigurou a relação entre voz (do narrador) e modo (de apresentação da narrativa), conferindo a este último o registro dos pontos de vista que circulam na narrativa (GENETTE, 1972, p. 203) ${ }^{4}$.

Os termos "ponto de vista", "perspectiva" e "focalização" são definidos no domínio da Teoria Literária por outros dicionários especializados, como, por exemplo, o de Reis e Lopes (2011) e o de Prince (2003) ${ }^{5}$. Nesses dicionários, nos quais o ponto de vista aparece como um fenômeno mais amplo da narração, em relação ao qual a perspectiva é um elemento de avaliação e a focalização um operador complexo (focalização interna, externa e não focalização), a menção direta ou indireta a Genette é constante e, em termos narrativos e fiduciários, contratual: os dicionaristas limitam-se a retomar os pressupostos genettianos, no máximo, complementando-os com pressupostos de outros autores. No Dicionário de

\footnotetext{
${ }^{4}$ Nosso interesse não é promover a arqueologia completa do conceito de "ponto de vista", mas observar como o Dicionário de Semiótica incorpora o conceito e seus correlatos e como procede a tomadas de posição mais ou menos explícitas nessa operação. Para uma exposição detalhada sobre o conceito de "ponto de vista", remetemonos à pesquisa $O$ ponto de vista em Semiótica: uma abordagem tensiva, desenvolvida sob nossa orientação por Maria Goreti Silva Prado no Curso de Mestrado do Programa de Pós-graduação em Linguística e Língua Portuguesa da FCLAr/Unesp (Proc. Fapesp n. 2011/04204-4).

5 Em Reis e Lopes (2011), a entrada "ponto de vista" não recebe propriamente definição, ela remete à entrada "perspectiva narrativa".
} 
Semiótica, embora o vulto de Genette seja também evocado direta ou indiretamente, o tipo de relação estabelecida com a tradição genettiana oscila entre o contratual e o polêmico.

O Dicionário classifica o ponto de vista como um conceito de definição "intuitiva e demasiadamente complexa" (GREIMAS; COURTÉS, 2008, p. 377), quase indefinível, que se distingue da perspectiva (esta não dependeria do sujeito observador e se assentaria na relação direta entre enunciador e enunciatário) e que depende das operações de focalização, já que estas selecionam diferentes tipos de observador.

$\mathrm{Na}$ entrada "ponto de vista", que define o termo como "um conjunto de procedimentos utilizados pelo enunciador para fazer variar o foco narrativo ${ }^{6}$, isto, é para diversificar a leitura que o enunciatário fará da narrativa", não se menciona o nome de Genette, mas, sim, os termos genettianos: os "esforços teóricos sucessivos [que] tentaram extrair daí [da noção de ponto de vista] articulações definíveis, tais como a colocação em perspectiva e a focalização". Esse é ponto de partida da elaboração do conceito de ponto de vista, ponto de formulação em que se reconhece sua generalidade e as tentativas de conceituação e formalização. Eis o terreno do empréstimo: empréstimos lexical e conceitual que alinham as preocupações da Semiótica com a enunciação dos textos narrativos aos princípios gerais da pesquisa genettiana sobre narração. Não é à toa que Genette é mencionado no prólogo do Dicionário como um teórico que tem "trabalhos valiosos" para a Semiótica da época (GREIMAS; COURTÉS, 2008, p. 14). No cenário do empréstimo, a mistura se dissemina enquanto valor, tendendo ao universal, multiplicando e dilatando o indistinto na extensidade das expansões discursivas.

Muitas vezes acoplada a um empréstimo metalinguístico, encontramos uma redefinição. O lexema "definição" tem no Houaiss as seguintes acepções: "delimitação exata, estabelecimento de limites", "decisão, determinação, resolução" e "manifestação clara; revelação". Nesses três conjuntos de acepções, podemos observar propriedades constitutivas da definição (delimitação, assunção e evidência) que a caracterizam pelos valores da triagem, de cunho absoluto, que operam por exclusão e concentração, com a intensidade que lhes é própria. O morfema "re", que remete, segundo o Houaiss, à "repetição, iteração", faz da redefinição uma operação de triagem mais explícita, na medida em que podemos pensar que a redefinição é uma operação de segundo grau que converte o "definido" em "redefinido".

É uma operação de redefinição que se dá ao final da entrada "ponto de vista", quando após um empréstimo iminentemente contratual, Greimas e Courtés (2008, p. 119) instauram a polêmica que demarca a definição semiótica do conceito: "um melhor conhecimento da dimensão cognitiva dos discursos narrativos levou-nos [...] a prever a instalação, no interior do discurso, do sujeito cognitivo dito observador". Essa (re)definição, ainda que tenha sido introduzida nas últimas linhas do verbete e sem maiores esclarecimentos, mostra-nos que o empréstimo do termo "ponto de vista" da herança de análise literária foi um empréstimo de integração parcial, já que não recobriu, ou melhor, não preencheu homogeneamente o empréstimo lexical, reservando nele lugar para a heterogeneidade conceitual-discursiva.

Se para Genette (1972, p. 183) a perspectiva, ao lado da distância, é uma modalidade essencial que regula a informação narrativa (PRINCE, 2003, p. 72) segundo um dado ponto de vista, para Greimas e Courtés (2008, p. 367), "diferentemente do ponto de vista, que necessita da mediação de um observador, a perspectiva vale-se da relação

\footnotetext{
${ }^{6}$ A expressão "foco narrativo", em inglês "focus of narration", foi cunhada por C. Brooks \& R. P. Warren em seu conhecido Understanding fiction (1943). O termo foi introduzido em língua francesa ("foyer narratif") provavelmente pelas mãos de Genette (1972, p. 203). Em português, como observam Reis e Lopes (2011, p. 165), o termo é "muito usual em estudos de proveniência brasileira".
}

Disponível em: http://seer.fclar.unesp.br/casa 
enunciador/enunciatário e depende dos procedimentos de textualização". Em Genette, a regulação da informação narrativa dá-se no interior do discurso narrativo pela perspectiva que orienta os procedimentos de focalização (REIS; LOPES, 2011, p. 323). Na Semiótica, de acordo com a definição citada do Dicionário, a perspectiva, por estar ligada à textualização, diz respeito à "escolha que [o enunciador] é levado a fazer quando da organização sintagmática dos programas narrativos", podendo conservar dois programas narrativos opostos para controlar sua manifestação textual e seu nível de explicitação ou, diferentemente, proceder por ocultação, seu correlato contrário, que se pauta pela "eliminação total da manifestação do programa narrativo do sujeito em proveito do programa do antissujeito (ou vice-versa") (GREIMAS; COURTÉS, 2008, p. 349).

Para os autores do Dicionário, perspectiva e ocultação são prerrogativas do enunciador em seu jogo com o enunciatário e não implicam a presença de um observador. Se esse posicionamento corresponde à ingenuidade dos célebres dicionaristas à época, não nos cabe aqui avaliar". O fato é que a entrada "perspectiva" em muito e desde o começo se afasta da definição genettiana, configurando um caso de empréstimo lexical e de redefinição discursiva.

Na entrada "focalização", única das três até aqui analisadas que fazem menção explícita à G. Genette, Greimas e Courtés (2008, p. 214) vão nos oferecer duas acepções do termo. A primeira consiste na semiotização narrativa do conceito genettiano, que é definido como a "delegação pelo enunciador a um sujeito cognitivo, chamado observador, e a sua instalação no discurso narrativo" ou, ainda, como um "procedimento de debreagem actorial". Essa primeira definição, de base genettiana, é dada pelos dicionaristas como provisória, já que não explicaria todos os modos de presença do observador e nem a constituição de espaços cognitivos parciais e, por isso, complexos. Procedimento curioso o do Dicionário de Semiótica, que semiotiza um conceito já existente, obedecendo estritamente aos seus limites, para, em seguida, dizer que o conceito é provisório, por não abarcar todos os casos. Esse é seguramente um caso de empréstimo total, mas um empréstimo que é feito na falta de um mais adequado ou na impossibilidade de criação terminológica ou conceitual, que serve bem ao caráter mais enciclopédico do que analítico que o Dicionário adota por vezes.

A segunda acepção de focalização do Dicionário, essa de caráter discursivo estritamente redefinicional, conceituará por focalização o procedimento, de base aspectual, que "consiste em inscrever (ou em delimitar), por aproximações concêntricas sucessivas, um ator ou uma sequência narrativa, em coordenadas espaço-temporais cada vez mais precisas". Essa acepção descreve a autonomia que o enunciador tem de concentrar e coordenar narrativas e sujeitos ao longo de uma narrativa e de colocá-los em foco quando achar necessário.

Como se pode perceber, o estudo das operações de empréstimo e redefinição do termo "ponto de vista" e de seus correlatos mostra-nos que o empréstimo lexical, que se dá como alternativa à criação terminológica, não implica necessariamente empréstimo conceitual-discursivo, já que certos termos são elaborados, do ponto de vista discursivo, por empréstimos seguidos de redefinições (o "ponto de vista", a "focalização") e outros por puras redefinições (a "perspectiva").

\footnotetext{
${ }^{7}$ No segundo tomo do Dicionário, na retomada da entrada "perspectiva". J. Fontanille reformulará a definição de Greimas e Courtés (2008, p. 367) segundo a qual a perspectiva prescindiria de um sujeito observador, afirmando que "pode-se considerar, por exemplo, que a perspectiva necessita da mediação de um observador tanto quanto o ponto de vista, desde que se defina o observador como um actante e não como um ator" (GREIMAS; COURTÉS, 1986, p. 165). Esse é um caso de redefinição discursiva no próprio âmbito da metalinguagem semiótica.
} 


\section{Considerações finais}

Este dicionário não fecha, abre rotas, sendeiros, caminhos...

Embora as posições de Peirce, Bastide e Benveniste evocadas anteriormente sobre a importância da terminologia na definição e criação de um novo campo científico não estejam exatamente em desuso - ainda que revelem um ideário científico das ciências naturais, caro aos séculos XVIII e XIX - a relevância e, sobretudo, a necessidade de uma metalinguagem rígida e distinta do "senso comum" vêm recebendo nas últimas décadas algumas críticas duras e nem sempre bem fundadas, é verdade, mas que dão margem certamente à reflexão, na medida em que colocam em risco as certezas mais correntes sobre a terminologia.

Um bom exemplo dessas críticas é a polêmica que causaram Sokal e Bricmont (1999) com sua acusação de que certos pensadores nas ciências humanas, dentre outras "imposturas intelectuais", extrapolam o bom-senso e a razão ao usarem sem rigor termos das ciências exatas para definirem vaga e metaforicamente algumas de suas ideias, o que sinaliza, no mínimo, que há algo que não vai bem no terreno da terminologia em humanidades.

Outro exemplo contundente, e mais recente, é a crítica que Gusmão (2012) faz a alguns pensadores das ciências sociais que teriam multiplicado o uso de termos e conceitos, distanciando-se do mundo do senso comum, de um possível "real" de que justamente esses conceitos deveriam supostamente dar conta. É isso que ele chamará em seu livro de "fetichismo do conceito", denunciando o enamoramento dos intelectuais pelos conceitos e termos em detrimento dos problemas que têm a resolver.

Na Semiótica de inspiração Greimasiana, embora o esforço de publicação de dois dicionários de Semiótica testemunhe um apreço intenso pelo rigor da metalinguagem, vimos como a posição de Greimas (1980) a esse respeito cuida de relativizar o papel da terminologia e da formalização e priorizar a atividade de conceitualização, considerada uma operação mais central e mais profunda na concepção da teoria, porque baseada em córpus concretos de análise. Nesse sentido, Greimas é seguido por Parret (1986) e Fabbri (1992) que, ainda que não abordem exatamente a centralidade da conceitualização no trabalho teórico, ao passo que reconhecem uma série de desafios ou inconsistências no trabalho dos dicionaristas dos dois tomos do Dicionário de Semiótica, deixam entrever que a atividade de fechamento metalinguístico, de acabamento monossêmico de um termo, não é algo fácil e natural, mas decorre de empréstimos e redefinições, em suma, de tomadas de posição mais ou menos conscientes e confessas.

Os empréstimos e redefinições realizados pela metalinguagem de inspiração greimasiana em relação a termos correntes em outras disciplinas do discurso não são sempre tão categóricos e nem tão fáceis de notar aparentemente quanto os que escolhemos para desenvolver este trabalho.

Os empréstimos, como os realizados em torno do termo "ponto de vista" e seus correlatos, pautam-se pela mistura, que convoca as origens e os desenvolvimentos do termo em questão e os reorganiza sem delimitar claramente sua extensão operatória dentro e fora da Semiótica. As redefinições, que atuam acopladas aos empréstimos, procedem essencialmente por triagem, selecionando no "conceito de partida" os elementos definicionais que podem ser aproveitados no "conceito de chegada" e lhes conferindo nova identidade (ou, simplesmente, alteridade) em relação ao repertório teórico de que foram extraídos. Essa identidade, 
dependendo da intensidade da visada adaptativa e da extensidade da redefinição, pode ser mais polêmica ou, ainda, mais contratual.

Dizer que a Semiótica, em relação à Linguística, à Antropologia, à Teoria Literária, à Filosofia ou às Teorias do Discurso de sua época, tenha elaborado sua metalinguagem tão somente por meio de empréstimos e redefinições está longe de corresponder a uma visão de conjunto sobre os fatos. A soma das operações de apropriação ou de diálogo com as tradições que lhe são anteriores deve certamente ser bem maior, já que, ao lado das operações de empréstimo e redefinição, poderíamos encontrar nos dois tomos do Dicionário de Semiótica, sob pena de inventário e definição exaustivos, operações de assimilação, exclusão, denegação, foraclusão, etc., que nos permitiriam, como indica a isotopia sugerida pelos dois últimos termos, fazer a "psicanálise" da metalinguagem semiótica ou, em outras palavras, estas mais exatas, a crítica metodológica da Teoria Semiótica por meio do percurso da elaboração e da circulação de sua metalinguagem.

Desse modo, vemos como em Semiótica, frequentemente, não estamos diante de um vocabulário tão estável e preciso quanto imaginamos, e muito menos completamente pertinente e adequado. Essas fissuras na couraça metalinguística impõem ao analista um quadro passional bem diferente daquele que costuma se instalar nos grandes momentos de fervor metalinguístico. Diante da imperfeição do modelo e de sua terminologia, o semioticista é provocado a exercer a vigilância, a desconfiança, a tolerância ou a humildade como formas de vida.

\section{REFERÊNCIAS}

BASTIDE, R. Introdução ao estudo do termo 'estrutura'. In: BASTIDE, Roger (Org.). Usos e sentidos do termo estrutura nas ciências humanas e sociais. Trad. Maria Heloiza Schabs Cappellato. Herder/Edusp: São Paulo, 1971.

BENVENISTE, É. Genèse du terme 'scientifique'. In: BENVENISTE, Émile. Problèmes de linguistique générale 2. Éditions Gallimard: Paris, 1974.

COURTÉS, J. Introduction à la sémiotique narrative et discursive. Paris: Hachette, 1976.

DUBOIS, J. Dicionário de linguística. 16. ed. Trad. Frederico Pessoa de Barros et al. São Paulo: Cultrix, 2011.

FABBRI, P. Pertinence et adéquation. Trad. Francis Debyser. Nouveaux Actes Sémiotiques, n. 19, Pulim, Limoges, 1992.

FIORIN, J. L. Prefácio. In: GREIMAS, A. J., COURTÉS, J. Dicionário de semiótica. Trad. Alceu Dias Lima et al. São Paulo: Contexto, 2008.

FONTANILlE, ; ZILBERBERG, C. Tensão e significação. Trad. Ivã Carlos Lopes, Luiz Tatit e Waldir Beividas. São Paulo: Discurso/Humanitas, 2001.

GENETTE, G. Figures III. Paris: Éditions du Seuil, 1972.

GREIMAS, A. J. Notes sur le métalangage. Actes Sémiotiques - Bulletin, vol. III, n. 13, março de 1980.

GREIMAS, A. J., COURTÉS, J. Sémiotique: dictionnaire raisonné de la théorie du langage. Paris: Hachette, 1979. 
Hachette, 1986.

Sémiotique: dictionnaire raisonné de la théorie du langage (tome 2). Paris: Dicionário de semiótica. Trad. Alceu Dias Lima et al. São Paulo: Contexto, 2008.

GROUPE D'ENTREVERNES. Analyse sémiotique des textes: introduction - théorie pratique. Lyon: Presses Universitaires de Lyon, 1979.

GUSMÃO, L. de. O fetichismo do conceito. São Paulo: Editora Topbooks, 2012.

HÉNAULT, A. Les enjeux de la sémiotique. Introduction à la sémiotique générale. Paris: PUF, 1979.

HJELMSLEV, L. Prolegômenos a uma teoria da linguagem. 2. ed. Trad. José Teixeira Coelho Netto. São Paulo: Perspectiva, 2003.

INSTITUTO ANTÔNIO HOUAISS. Houaiss Eletrônico 1.0. CD-Rom. São Paulo: Objetiva, 2009.

KRIEGER, M. da G. Terminologia técnico-científica: políticas lingüísticas e Mercosul. Cienc. Cult., São Paulo, v. 58, n. 2, junho de 2006. Disponível em: $<$ http://cienciaecultura.bvs.br/scielo.php?script=sci_arttext\&pid=S000967252006000200017\&lng=en\&nrm=iso>. Acesso em: 17 Set 2012.

PARRET, H. Les avenirs de la sémiotique. Actes Sémiotiques - Bulletin, vol. IX, n. 38, Besançon, junho de 1986.

PEIRCE, C. S. A ética da terminologia. In: PEIRCE, Charles Sanders. Semiótica. 2. ed. Trad. José Teixeira Coelho Netto. Perspectiva: São Paulo, 1995.

PRINCE, G. A dictionary of narratology. Lincoln: University of Nebraska Press. 2003.

NORMAND, C. Les mots en emploi: lexique et discours. In: NORMAND, Claudine (Org.). La quadrature du sens. Paris: PUF, 1990.

REIS, C; LOPES, A.C. M. Dicionário de narratologia. 7. ed. Coimbra: Almedina, 2011.

SAUSSURE, F. de. Cours de linguistique générale. Notas e comentários de Tullio de Mauro. Paris: Payot, 2005. Écrits de linguistique générale. Paris: Gallimard, 2002.

SOKAL, A; BRICMONT, J. Imposturas Intelectuais: o abuso da ciência pelos filósofos pós-modernos. Trad. Max Altman. Rio de Janeiro: Record, 1999. 
CASA, Vol.10 n.2, dezembro de 2012

\section{ANEXOS}

ANEXO A - Verbete "Ponto de vista" no Dicionário de Semiótica

\section{PONTO DE VISTA}

\section{fr. Point De Vue; ingl. Point of VieW}

Designa-se, geralmente, pela expressão ponto de vista um conjunto de procedimentos utilizados pelo enunciador* para fazer variar o foco narrativo, isto é, para diversificar a leitura que o enunciatário fará da narrativa, no seu todo, ou de algumas de suas partes. Esta noção é intuitiva e demasiadamente complexa: esforços teóricos sucessivos tentaram extrair daí articulações definíveis, tais como a colocação em perspectiva e a focalização; um melhor conhecimento da dimensão cognitiva * dos discursos narrativos levou-nos, igualmente, a prever a instalação, no interior do discurso, do sujeito cognitivo dito observador.

$\rightarrow$ Perspectiva, Focalização, Observador.

\section{ANEXO B - Verbete "Perspectiva" no Dicionário de Semiótica}

\section{Perspectiva s. $\mathrm{f}$.}

\section{fr. Perspective; ingl. Perspective}

1. Diferentemente do ponto de vista, que necessita da mediação de um observador*, a perspectiva vale-se da relação enunciador*/enunciatário e depende dos procedimentos de textualização*.

2. Fundada na estrutura polêmica* do discurso narrativo, a colocação em perspectiva consiste, para o enunciador, na escolha que é levado a fazer quando da organização sintagmática dos programas* narrativos, tendo em conta as coerções da linearização* das estruturas narrativas. Assim, por exemplo, a narração de um assalto pode pôr em relevo o programa narrativo do assaltante ou o do assaltado; do mesmo modo, a narrativa proppiana privilegia o programa do herói, em detrimento do programa do vilão.

3. Enquanto a ocultação tem por efeito a eliminação total da manifestação* do programa narrativo do sujeito em proveito do programa do anti-sujeito (ou viceversa), a perspectiva conserva os dois programas opostos, privilegiando - em relação a instância receptora do enunciatário - um dos programas que é, então, amplamente explicitado, em detrimento do outro, só fragmentariamente manifestado.

\section{$\rightarrow$ Ponto de vista, Focalização, Ocultação.}


CASA, Vol.10 n.2, dezembro de 2012

\section{ANEXO C - Verbete "Focalização" no Dicionário de Semiótica}

\section{$\overline{\text { Tृ̊n }}$ FoCALIZAÇÃo s. f. \\ FR. FOCALISATION; INGL. FOCALIZATION}

1. O termo focalização serve para designar, na esteira de G. Genette, a delegação feita pelo enunciador* a um sujeito cognitivo*, chamado observador, e a sua instalação no discurso narrativo: esse procedimento permite, assim, apreender quer o conjunto da narrativa, quer certos programas pragmáticos*, apenas do "ponto de vista" desse mediador. Diferentes tipos de focalização - que é um procedimento de debreagem* actancial-podem ser distinguidos segundo o modo de manifestação do observador: este, às vezes, permanece implícito, ou aparece, em outros casos, em sincretismo com um dos actantes* da comunicação (o narrador* ${ }^{*}$, por exemplo) ou um dos actantes da narração (um sujeito pragmático*, por exemplo). Notarse-á, entretanto, que esse conceito de focalização que, conjugado com a colocação em perspectiva*, esgota a antiga noção de "ponto de vista", é ainda provisório: ele não explica todos os modos de presença do observador (por exemplo, no caso da aspectualização*), nem explica a constituição dos espaços cognitivos* parciais, caracterizados pela presença - no interior dos programas pragmáticos - de dois sujeitos cognitivos em comunicação.

2. Denomina-se também focalização - considerando-se agora não mais o sujeito focalizador, mas o objeto focalizado - o procedimento que consiste em inscrever (ou em delimitar), por aproximações concêntricas sucessivas, um ator* ou uma sequência* narrativa, em coordenadas espaço-temporais cada vez mais precisas. Para fazer isso, o enunciador dispõe não somente das possibilidades oferecidas pela localização espaço-temporal, mas também, e sobretudo, do procedimento de encaixe, graças ao qual uma puntualidade* ou uma duração pode ser inscrita em uma outra duração, um espaço* em outro espaço.

$\rightarrow$ Observador, Perspectiva, Localização espaço-temporal, Encaixe. 